\title{
As relações do conhecimento produzido na área de arquivologia com a ciência da informação
}

\author{
Nilcéia Lage Medeiros \\ Mestra em administração pela Faculdade Novos Horizontes, \\ especialista em gestão de arquivos e documentos pelo IEC da \\ Puc Minas, bibliotecária formada pela UFMG e graduanda \\ em arquivologia pela UFMG. \\ E-mail: biblioteca@globo.com
}

\author{
Thaís Nodare \\ Graduanda em arquivologia pela Escola de Ciência da \\ Informação da Universidade Federal de Minas Gerais, MG, \\ Brasil. \\ E-mail: tatanodare@hotmail.com
}

\section{Carlos Alberto Ávila Araújo}

Doutorado em ciência da informação, mestrado e graduação em comunicação social pela Universidade Federal de Minas Gerais. Pós-doutorando pela Faculdade de Letras da Universidade do Porto, Portugal.

E-mail: casal@eci.ufmg.br

\section{Resumo}

Este estudo, realizado em 2009, objetiva aplicar análises bibliométricas ao periódico Arquivo \& Administração, da área de Arquivologia. Elaboraram-se planilhas com os seguintes dados coletados em 21 trabalhos publicados entre 2004 e 2006: autoria, vinculação dos autores, vinculação dos trabalhos às correntes teóricas da Ciência da Informação, caracterização das referências quanto aos autores citados, idioma e ano. Os dados foram analisados à luz de seis correntes teóricas da Ciência da Informação, buscando-se identificar a relação do conhecimento produzido na área de Arquivologia com o da área da Ciência da Informação. A análise dos dados indicou a existência de uma estreita relação do conhecimento produzido na área de Arquivologia com o conhecimento gerado pela área da Ciência da Informação. Tal afirmação apoia-se, primeiro, na categorização das correntes teóricas da Ciência da Informação que puderam ser identificadas nos trabalhos selecionados; e, segundo, na identificação dos autores citados na Ciência da Informação e que também foram identificados nos fascículos do periódico analisado.

\section{Palavras-chave}

Correntes teóricas da ciência da informação. Arquivo \& administração. Arquivologia.

\author{
Relationship between the knowledge \\ created in the area of Archive Studies and \\ that generated in the field of Information \\ Science
}

Abstract

This research, carried out in 2009, aims to apply bibliometric analysis to the journal Archive \& Administration, from the field of Archive Studies. Spreadsheets were designed with the following data picked out from 21 works published between 2004 and 2006: authorship, authors' commitments, any linking of the publication to the theoretical currents in Information Science, characterization of the references regarding the author quoted, the idiom, and the year of publication. Data were analyzed in the light of six theoretical currents from the Information Science, trying to identify the relationship between the knowledge created in the area of Archive Studies and that generated in the field of Information Science. Data analysis indicated the existence of a close relationship between the kind of knowledge generated in the Information Science area. This statement is based, firstly, on the characterization of the theoretical currents in Information Science identified in the works singled out; and secondly, on the identification of the authors quoted in Information Science, also found in issues of the aforementioned journal.

\section{Keywords}

Information Science theoretical currents. Archive \& Administration. Archive studies.

\section{INTRODUÇÃO}

A arquivologia nasceu essencialmente ligada à prática (conjunto de técnicas) de guardar, preservar e organizar os registros do conhecimento humano. No século XIX, começa o processo de sua consolidação como disciplina científica, inicialmente como uma disciplina auxiliar da história e da administração até seu encontro, já no século XX, com a ciência da informação, ciência normalmente caracterizada como social, interdisciplinar e pós-moderna. 
No âmbito da ciência da informação, ao longo de seu desenvolvimento, surgiram diferentes correntes teóricas, resultantes de diferentes "programas de pesquisa” (GONZÁLEZ DE GÓMEZ, 2000), aqui citadas com suas respectivas agendas de investigação (ARAÚJO, 2009):

a) estudos quantitativos sobre a informação - tiveram origem com a teoria matemática da comunicação, de Shannon e Weaver, buscando compreender o processo linear de transferência da informação;

b) estudos vinculados à teoria sistêmica - inspirados na biologia, em uma lógica cíclica dos processos (processamento da informação em um sistema), trazendo o conceito de sistema de informação;

c) teoria crítica - com forte base na filosofia e na sociologia, enfocando o empoderamento, privilégios, recursos, desigualdades e contradições em termos da informação e sua dimensão social;

d) estudos em representação e classificação - originados de uma época preocupada em criar seus repertórios e sistemas de classificação bibliográfica, focados na atribuição de significado, de representação e linguagem;

e) estudos sobre as redes e fluxos da informação inicialmente voltados para os contextos científico e tecnológico, e atualmente voltados para os âmbitos organizacional e empresarial, prendem-se à gestão da informação e ao conhecimento, mobilizando conceitos como conhecimento tácito, colégio invisível, intercâmbio, vantagem competitiva e tomada de decisão;

f) estudos de usuários - veem a informação na perspectiva do usuário, analisando suas necessidades e seu comportamento em relação à informação.

Do ponto de vista paradigmático (CAPURRO, 2003), a ciência da informação vai de um paradigma físico, em que focaliza o tratamento e a organização da informação para alimentar sistemas computacionais, para um cognitivo, em que o objetivo continua sendo focalizar o tratamento e a organização da informação, porém os processos se baseiam no paradigma psicológico, para satisfazer os usuários individuais, chegando a um paradigma social, em que os processos são baseados no contexto social/ cultural, objetivando a construção da informação contextualizada.

A discussão sobre o impacto das tecnologias da informação e comunicação acabou por deslocar a ciência da informação, que até então era voltada para a custódia, para um "paradigma pós-custodial" (SILVA, 2006).

Assim, estudar os caminhos evolucionários da ciência da informação significa melhor compreender o relacionamento desta ciência com a arquivologia. A ciência da informação e a arquivologia contemplam a informação em suas atividades teóricas e pragmáticas. Fonseca (2005) denuncia que a ciência da informação, em muitos momentos, não abarca a arquivologia e que a arquivologia não se vê como área da ciência da informação. Vai contra Thomassem (1996) quando afirma que "entre as mudanças provocadas pelos avanços tecnológicos, a mais estimulante é que a Arquivologia deixou de ser uma ciência auxiliar da história para converter-se em uma disciplina autônoma no campo das ciências da informação" (citado por JARDIM, 1998, p. 3).

Pretende-se aqui analisar bibliometricamente dados coletados em 21 trabalhos publicados de 2004 a 2006 no periódico Arquivo \& Administração. Os dados selecionados foram autoria, vinculação dos autores, vinculação dos trabalhos às correntes teóricas da ciência da informação, caracterização das referências quanto aos autores citados, idioma, ano e tipologia. Busca-se analisar, à luz das seis correntes teóricas da ciência da informação, o conhecimento produzido na área de arquivologia e sua relação com a ciência da informação.

\section{O PER I Ó D I C O ARQUIVO E ADMINISTRAÇÃO}

Antes de apresentar especificamente o periódico pesquisado, optou-se por fazer breve contextualização do universo das publicações voltadas para a área de arquivologia. 
Na plataforma Qualis encontra-se a Revista do Arquivo Público Mineiro - História e Arquivística, periódico que há mais de 100 anos publica artigos, ensaios, documentos e instrumentos de pesquisa voltados para a historiografia mineira.

Os outros dois periódicos que estão listados na plataforma Qualis, Arquivistica.Net e Cadernos de Biblioteconomia, Arquivística e Documentação, foram descontinuados.

Vale salientar que, para a comunidade científica, diante do número reduzido de periódicos voltados para a arquivologia, a submissão de trabalhos também deve levar em conta os periódicos de outras áreas do conhecimento, principalmente ciência da informação, história, administração e ciência da computação.

Em relação ao periódico estudado, Arquivo \& Administração, é editado pela Associação dos Arquivistas Brasileiros (AAB), e iniciou-se em 1972, sem a pretensão de ser um periódico científico ou de preocupar-se com a normalização. Divulgava textos, notícias, fotos, informes sobre cursos e eventos. Conforme Pupim (2009), a partir do volume 6, os trabalhos passam a submeter-se às diretrizes para publicação. De 1972 a 1999, foram 35 edições disponíveis on-line. Voltou a ser publicado em 2004 com edições disponíveis em formato tradicional (papel) e com periodicidade variando entre semestral e anual.

Em seu primeiro editorial, a área era vista como uma disciplina auxiliar da administração e da história, demonstrando claramente não se incluir na ciência da informação. De 1972 até 2008, ocorreram mudanças paradigmáticas, e o disposto no citado editorial já não fazia parte da realidade da área.

Nos primeiros fascículos não se percebe a preocupação com elementos que dão origem a um periódico. Contudo, cada fascículo difere do seguinte. A normalização, no entanto, deixou de ser seguida pelos autores. Somente no volume 6 é que os trabalhos passaram a submeter-se às diretrizes para publicação.

O periódico já foi objeto de estudo científico. O estudo de Pupim (2009) deu-se em relação aos volumes publicados entre 1972 e 1999 (fascículos disponíveis na Internet). Entre os resultados encontrados, destacam-se os seguintes:

a) o ano de 1998 foi pródigo em artigos fonte e citações;

b) o idioma nacional é predominante, com $70 \%$. No entanto, muitas dessas obras foram traduzidas de outras línguas, o que leva à conclusão que o português era o idioma preferido. Como segunda língua mais citada pelos autores dos artigos fontes, aparece o inglês, com $14 \%$;

c) no âmbito das cidades, o Rio de Janeiro aparece em 33\% das citações geográficas. Isso, muito provavelmente, deve-se ao fato de ser a sede da Associação dos Arquivistas Brasileiros;

d) Carol Couture e Jean-Yves Rosseau tiveram seus trabalhos citados (tabela 1) em quatro momentos,

TABELA 1

\section{Autores mais citados, segundo Pupim (2009)}

\begin{tabular}{|c|c|}
\hline Autoria & $\begin{array}{l}\text { Quantidade } \\
\text { de ciracóes }\end{array}$ \\
\hline Avtores com duas ou menos citaçöes & 285 \\
\hline Brasil. Esfera Federal & 29 \\
\hline T. R. Schellenberg & 12 \\
\hline José Maria Jardim & 8 \\
\hline Nitza Teixeira Soares & 7 \\
\hline Michel Duchein & 7 \\
\hline Marilema Leite Paes & 7 \\
\hline Sherelyn Ogden & 6 \\
\hline Josè Honório Rodrigyes & 5 \\
\hline Associaçāo dos Arquivistas Holandeses & 4 \\
\hline Carol Couture & 4 \\
\hline Jean-Yves Rosseav & 4 \\
\hline Maria Aparecida dos Santos & 4 \\
\hline Jean-Jacques Valette & 3 \\
\hline Louis Starr & 3 \\
\hline Arquivo Nacional & 3 \\
\hline M. Bavdot & 3 \\
\hline He bisa Liberalli Bellotto & 3 \\
\hline Ana Maria de Camargo & 3 \\
\hline Fundaçāo Getútio Vargas & 3 \\
\hline Boris Kossoy & 3 \\
\hline Jacques Le-Goff & 3 \\
\hline $\begin{array}{l}\text { REUNION Regional de Expertos para el } \\
\text { Desarrollo de los Arquivos Nacionales en } \\
\text { América Latina }\end{array}$ & 3 \\
\hline Total & 412 \\
\hline
\end{tabular}

Fonte: Pupim, 2009.

Ci. Inf., Brasília, DF, v. 39 n. 2, p.44-53, maio/ago., 2010 
sendo tais autores, na contemporaneidade mundial, de extrema importância na arquivologia.

Para Pupim (2009), há muitos autores com menos de duas citações. Muitos deles, como Luciana Durante, Suzanne Briet, Maria Odila Fonseca, Antonio Heredia Herrera e Miriam Lifchitz Moreira Leite são muito importantes, indicando que a arquivologia se encontrava em pleno desenvolvimento teórico.

\section{APRESENTAÇÃO E ANÁLISE DOS DADOS}

A análise do periódico foi realizada entre os fascículos publicados entre 2004 e 2006, corte necessário para que este estudo pudesse ser entregue no tempo estipulado. O critério adotado consistiu em descartar trabalhos que não tivessem cunho científico, a saber: os editoriais; a Carta para a Preservação do Patrimônio Arquivístico Digital Brasileiro, de autoria de Claudia Lacombe Rocha e Margareth da Silva, publicada em 2004; e o Debate entre Terry Eastwood e Theo Thomassen, publicado em 2007. O processo de seleção dos trabalhos de cunho científico para análise levou em consideração o aparecimento dos termos "Arquivologia", "Arquivística(o)", "Archivística", "Arquivo", "Archivo" ou "Arquivista" nos títulos, palavras-chave ou Introdução. Dos 36 trabalhos publicados de 2004 a 2008, dois não continham tais termos:

1) Governo Eletrônico, Gestão da Informação e Exclusão Informacional / José Maria Jardim, Ano 2004;

2) Alguns aspectos del Notariado en España: origenes y evolución / María José Justo Martín, Ano 2008, jul./dez.
Em relação ao trabalho intitulado "Archives for all: the importance of archives in society", de Randall C. Jimerson, de julho/dezembro de 2008, o referido periódico também publicou sua versão traduzida para o português, por isso a versão em inglês não foi analisada.

Assim, dos 36 trabalhos restaram 33. Porém, serão analisados 21, isto é, somente os publicados de 2004 a 2006, corte necessário em função do tempo disponível para a pesquisa.

\section{APRESENTAÇÃO E ANÁLISE DOS DADOS DOS TRABALHOS}

Temática dos trabalhos, segundo as correntes teóricas da ciência da informação

Considerando as seis correntes teóricas da ciência da informação aqui apresentadas, buscou-se identificar e analisar sua incidência nos 21 trabalhos analisados, por meio de aproximações da maneira como a informação - a informação arquivística e a instituição arquivo - é tratada. Os resultados encontrados foram os seguintes: nove trabalhos vinculados à teoria sistêmica, quatro às teorias da representação e aos estudos de usuários e três às teorias de fluxos e redes, um à teoria crítica. Nenhum se vinculou à teoria matemática (tabela 2).

Sobressaíram os artigos ligados à teoria sistêmica, notadamente sobre as discussões relacionadas com ciclo de vida dos documentos, gestão de documentos digitais e preservação de documentos. Seguem-se artigos vinculados às teorias da representação - temas

TABELA 2

Categorização dos 21 trabalhos segundo as correntes teóricas da CI

\begin{tabular}{c|r|r|r|r|r}
\hline $\begin{array}{c}\text { Ano de Fublicaço } \\
\text { Teoria }\end{array}$ & Sitémica & Crítica & $\begin{array}{r}\text { Represeutacio é } \\
\text { Clasificatoria }\end{array}$ & $\begin{array}{r}\text { Fluxas } \\
\text { e redes }\end{array}$ & $\begin{array}{r}\text { Estudo de } \\
\text { usuário }\end{array}$ \\
\hline 206 & 3 & 1 & 1 & 1 & 2 \\
2006 & 5 & - & 2 & 1 & 1 \\
2004 & 1 & - & 1 & 1 & 1 \\
\hline
\end{tabular}

Fonte: Os autores. 
como organização da informação, ordem original dos documentos, representação e recuperação da informação; e estudos de usuários - condições humanas e sociais de produção da informação, estudos sobre fluxos e redes, gestão da qualidade, sociedade da informação, gestão da informação e do conhecimento e políticas públicas arquivísticas; e, por fim, com apenas uma incidência, teoria crítica - formação do arquivista como um profissional crítico. Não foram identificados trabalhos ligados à abordagem matemática.

Dos 21 trabalhos, nove, ou 43\%, foram categorizados na teoria sistêmica, percentual que pode ser explicado pelo fato de seis trabalhos abordarem a preservação de documentos e dois a gestão de documentos digitais, sendo o fascículo do primeiro semestre de 2005 o que mais pesou para este resultado. Há que se pesquisar se tais trabalhos são frutos do projeto $\mathrm{CPBA}^{1}$.

\section{Autoria dos trabalhos}

Foram identificadas 24 autorias nos 21 trabalhos selecionados (tabela 3):

TABELA 3

Número de trabalhos publicados, por autoria

\begin{tabular}{|c|c|}
\hline Autoria dos trabalhos & $\begin{array}{r}\mathrm{N}^{\circ} \text { de } \\
\text { trabalhos } \\
\text { publicados }\end{array}$ \\
\hline $\begin{array}{l}\text { Alicia Barmard AMOZURRUTIA } \\
\text { Arien Gonzalez CRESPO } \\
\text { Armando B. Matheiro da SILVA }\end{array}$ & $\begin{array}{l}1 \\
1 \\
2\end{array}$ \\
\hline Georgete MedLeg RODRIGUES & 1 \\
\hline Ingrid $B E C K$ & 2 \\
\hline $\begin{array}{l}\text { Ivone Pereira de SA \& Paulo Xavier dos SANTOS } \\
\text { Joảo VIEIRA } \\
\text { Jogé Maria JARDIM }\end{array}$ & $\begin{array}{l}1 \\
1 \\
2\end{array}$ \\
\hline $\begin{array}{l}\text { Julio Cesar CARDOSO \& André Ricardo LUZ } \\
\text { Lvcia Maria Veloso de OLIVEIRA. }\end{array}$ & $\begin{array}{l}1 \\
1\end{array}$ \\
\hline Lvciana DURANTI & 1 \\
\hline Maria Luiza de Almeida CAMPOS & 1 \\
\hline $\begin{array}{l}\text { Mayra M. Mena MUGICA } \\
\text { Rosely Curi RONDINELLI \& Claudia Lacombe ROCHA }\end{array}$ & $\begin{array}{l}1 \\
1\end{array}$ \\
\hline Sérgio Conde de A toite SILVA & 1 \\
\hline $\begin{array}{l}\text { Surama Alves MARTINS } \\
\text { Theo THOMASSEM } \\
\text { Wilson Sartiago da SILVA }\end{array}$ & $\begin{array}{l}1 \\
1 \\
1\end{array}$ \\
\hline Total & 21 \\
\hline
\end{tabular}

Fonte: Os autores.

1 Após a finalização dessa pesquisa foram publicados um volume em 2009 e outro em 2010.
Entre os autores, três publicaram dois trabalhos nos fascículos analisados: Armando B. Malheiro da Silva, Ingrid Beck e José Maria Jardim. Os resultados mostram que existe considerável dispersão em relação à produção científica no campo.

Com número reduzido de trabalhos, optou-se por não analisar o resultado do cruzamento dos dados relativos às correntes teóricas da ciência da informação com os 24 autores. Além disso, esta pesquisa carece de maior aprofundamento sobre a área de atuação dos autores para que sejam analisadas as temáticas e abordagens.

\section{Vinculação dos autores dos trabalhos}

Foram identificadas as seguintes vinculações para os 24 autores (tabela 4):

TABELA 4

Vinculação institucional dos autores

\begin{tabular}{|c|c|}
\hline Instituiçào & $\mathrm{N}^{\circ}$ \\
\hline $\begin{array}{l}\text { Academia Reirwardt Ams terdam } \\
\text { Casa de las Américas }\end{array}$ & $\begin{array}{l}1 \\
1\end{array}$ \\
\hline $\begin{array}{l}\text { CPBA } \\
\text { Edificios e Mommentos } \\
\text { FIOCRUZ * }\end{array}$ & $\begin{array}{l}2 \\
1 \\
2\end{array}$ \\
\hline InterPares & 1 \\
\hline $\begin{array}{l}\text { Secretaria Salvd México } \\
\text { Serviço de Arquivo do Museu do Indio * } \\
\text { UFF }\end{array}$ & $\begin{array}{l}1 \\
1 \\
5\end{array}$ \\
\hline$U_{n B}$ & 1 \\
\hline UNIRIO* & 3 \\
\hline Universidad de La Habana & 1 \\
\hline Universidads do Porto & 2 \\
\hline Arquivo Nacional * & 1 \\
\hline Não indicado & 1 \\
\hline Total & 24 \\
\hline
\end{tabular}

* Autoria coletiva.

Fonte: Os autores.

Com base na análise deste quesito, optou-se por categorizar as instituições a que os autores estão vinculados pela localização geográfica: nacional / Rio de Janeiro (14), nacional (1), internacional (8) e não indicada (1).

Ci. Inf., Brasília, DF, v. 39 n. 2, p.44-53, maio/ago., 2010 
Em relação às instituições a que os autores estão vinculados, tanto nesta pesquisa, quanto na de Pupim (2009) há predomínio geográfico do Rio de Janeiro. Para Pupim (2009), a taxa de 58\% para o Rio de Janeiro foi relacionada ao fato de a sede da AAB ser nessa localidade. Tal conclusão pode ser relativizada levando-se em conta a rede de contatos da associação, bem como ao número de instituições voltadas para a arquivologia e que estão sediadas no Rio de Janeiro e, consequentemente, o número de mestres e doutores vinculados às instituições de ensino do Rio (UFF e IBICT)

Já a presença de oito autores internacionais impactou com 34\% de vinculações internacionais. Há que se pesquisar em trabalhos futuros a vinculação não identificada na publicação.

Com número reduzido de trabalhos, optou-se por não analisar o resultado do cruzamento dos dados relativos às correntes teóricas da ciência da informação e as instituições a que os 24 autores são vinculados. Além disso, esta pesquisa carece de maior aprofundamento sobre a área de atuação dos autores para que sejam analisadas as temáticas e abordagens.

\section{APRESENTAÇÃO E ANÁLISE DOS DADOS DAS REFERÊNCIAS}

A etapa a seguir concentrou-se nas referências dos artigos, analisadas em relação a quatro quesitos.

O primeiro é o número de referências contidas nos 21 trabalhos analisados de 2004 a 2006: 2006 (162), 2005 (119) e 2004 (113).

Já os números de trabalhos analisados entre 2004 e 2006, com respectivas referências, foram os seguintes: 2004 (quatro trabalhos e 113 referências), 2005 (nove trabalhos e 119 referências), e 2006 (oito trabalhos e 162 referências).

O ano de 2004 teve apenas quatro trabalhos, que citaram 113 referências. O de 2005 teve o maior número de trabalhos, (nove), que citaram 119 referências. O de 2006 teve oito trabalhos, com 162 referências. Levando-se em conta o elevado número de trabalhos publicados em 2005 sobre preservação, conforme analisado anteriormente, pode-se inferir que houve crescente aumento nas citações, sinalizando para o amadurecimento científico dessa área.

Em relação ao número de referências por autor (tabela. 5), Silva aparece em primeiro lugar, com 68 referências, seguido por Oliveira, com 49; Jardim, com 39; Rodrigues, com 38; e Martins, com 30. Há que se considerar que o primeiro e o terceiro lugar publicaram dois artigos cada um. Theo Thomassem não indicou referências.

TABELA 5

Número de referências citadas pelos 21 autores

\begin{tabular}{|c|c|}
\hline Autor & $\begin{array}{r}N^{\circ} \text { de } \\
\text { Referêucias }\end{array}$ \\
\hline Amando B Maheiro da SIIVA & $68^{\circ}$ \\
\hline Lucia Mraia Veloso da OLIVERA & 49 \\
\hline Jose Maria J ARDNM & $39 *$ \\
\hline Georgote MedIeg RCDRIGUES & 38 \\
\hline Suzana Alves MCARTINS & 30 \\
\hline Jutio Ceisr CARDOSO \& André Ricardo LUZ & 24 \\
\hline Ivone Pereira de SA \& Pauto Xavier dos S.ANTOS & 23 \\
\hline Wilson Santiago da SILVA & 23 \\
\hline Ingrid $B E C K$ & $20^{\circ}$ \\
\hline Maria Luiza de Almeida CANDOS & 17 \\
\hline Alícia Bamard ANOZURRUTIA & 16 \\
\hline Nayra M Mena MucreA & 15 \\
\hline Sèrgio Conde de Atbite SII VA & 11 \\
\hline Rosely Curi RONDINEII \& Clavdia Laccen be ROCHA & 10 \\
\hline $\begin{array}{l}\text { Luciana DURANTI } \\
\text { Joäo VIEIRA } \\
\text { Arien Gonzalez CRESPO }\end{array}$ & $\begin{array}{l}7 \\
3 \\
1\end{array}$ \\
\hline Theo THOMCASSEM & 0 \\
\hline Total & 394 \\
\hline
\end{tabular}

* Cada autor publicou dois trabalhos.

Fonte: Os autores.

Além disso, há que se analisar o número de autocitações (tabela 6)

TABELA 6

Número de referências versus número de autocitações

\begin{tabular}{|c|c|c|}
\hline Autores & $\begin{array}{r}N^{\circ} \text { de } \\
\text { re ferências } \\
\text { citadas }\end{array}$ & $\begin{array}{l}\text { No de } \\
\text { auto- } \\
\text { cir açốes }\end{array}$ \\
\hline Armando B. Malheiro da SILVA" & 15 & 9 \\
\hline Clavdia Lacombe ROCHA & & 2 \\
\hline Georgete Med Leg ROD RI GUES & 6 & 6 \\
\hline Ingrid BECK* & 3 & 3 \\
\hline José Maria JARDIM* & 19 & 6 \\
\hline Lvcia Maria Veloso de OLIVEIRA & & 1 \\
\hline Lvciana DURALVTI & 6 & 3 \\
\hline $\begin{array}{l}\text { Maria Luiza de Almeida CA.MPOS } \\
\text { Rosely Curi RONDNELLI }\end{array}$ & & $\begin{array}{l}1 \\
2\end{array}$ \\
\hline Sèrgio Conde de Albite SILVA & 3 & 1 \\
\hline
\end{tabular}

* Cada autor publicou dois trabalhos.

Fonte: Os autores. 
A análise das autocitações mostra que Rodrigues e Beck são citadas apenas em trabalhos de sua própria autoria e que Silva, dentre as 15 citações, tem nove autocitações.

Por fim, apresenta-se o número de referências em relação às correntes teóricas da ciência da informação: sistêmica (110), crítica (38), classificatória (79), redes e fluxos de informação (63), e estudo de usuários (104).

Levando-se em conta que foram categorizados nove trabalhos na teoria sistêmica, quatro na teoria da representação e classificação, quatro em estudos de usuários, três em estudos de redes e fluxos da informação e um em teoria crítica, apresentam-se os resultados:

A teoria crítica apresentou o maior número de referências por trabalho, seguida de estudos de usuários, redes e fluxos da informação, classificatória e, por fim, sistêmica.

Com número reduzido de trabalhos, optou-se por não analisar o resultado do cruzamento dos dados relativos às correntes teóricas da ciência da informação e o número de referências.

\section{Idioma das referências}

Foram identificadas 394 referências nos 21 trabalhos selecionados, sendo 191 nacionais e 203 internacionais (tabela 7):

\section{TABELA 7}

\section{Referências nacionais e internacionais citadas} pelos 21 autores

\begin{tabular}{|c|c|c|}
\hline Aut or & $\begin{array}{c}\mathrm{N}^{\circ} \mathrm{de} \\
\text { referências } \\
\text { nacionais } \\
\text { (Brasil) }\end{array}$ & $\begin{array}{c}\mathrm{N}^{\circ} \mathrm{de} \\
\text { referências } \\
\text { internacionais }\end{array}$ \\
\hline $\begin{array}{l}\text { A tícia Bamard AMO ZURRU TIA } \\
\text { Arien Gonzilez CRE SPO }\end{array}$ & - & $\begin{aligned} 16 \\
1\end{aligned}$ \\
\hline $\begin{array}{l}\text { Armando B. Ma theiro da SILVA* } \\
\text { Geor gete MedLeg RODRIGUES }\end{array}$ & $\begin{array}{l}14 \\
20\end{array}$ & $\begin{array}{l}54 \\
18\end{array}$ \\
\hline $\begin{array}{l}\text { Ingrid BECK* } \\
\text { Ivone Pereira de SA e Pavio Xavier dos SANTOS }\end{array}$ & $\begin{array}{l}10 \\
18\end{array}$ & $\begin{array}{r}10 \\
5\end{array}$ \\
\hline Jo 3̈० VIEIRA & 20 & 3 \\
\hline $\begin{array}{l}\text { Jose Maria JAFDIM* } \\
\text { Julio Cisar CA RD OSO e André Ricardo LUZ }\end{array}$ & 17 & 7 \\
\hline $\begin{array}{l}\text { L veia Maria Veloso de OLIVEIRA } \\
\text { Luciana DURANTI }\end{array}$ & 18 & 31 \\
\hline Maria Luiza de Almeida CAMPOS & 14 & 3 \\
\hline Mayra M. Mena MUGICA & - & 15 \\
\hline Rosely Curi RONDINELLI e Clavdia Lacombe ROCHA & 7 & 3 \\
\hline Sèrgio Conde de Albite SILVA & 4 & 7 \\
\hline Suzana Alves MARTMS & 30 & - \\
\hline Thao THOMASSEM & 0 & 0 \\
\hline Wilson Santia go da SILVA & 19 & 4 \\
\hline Total & 191 & 203 \\
\hline
\end{tabular}

* Cada autor publicou dois trabalhos.

Fonte: Os autores.
Dos oito autores estrangeiros, somente Armando B. Malheiro da Silva citou também referências nacionais (tabela 8). Este resultado pode ser explicado pelo contato do autor com a comunidade científica brasileira, tendo publicado dois trabalhos nos fascículos analisados.

\section{TABELA 8}

\section{Idiomas das referências citadas pelos 21 autores}

\begin{tabular}{|c|c|c|c|c|c|c|}
\hline Autor & 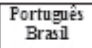 & $\begin{array}{l}\text { Portuguếs } \\
\text { Portugal }\end{array}$ & Espaubol & Francés & Inglês & Outro \\
\hline $\begin{array}{l}\text { Alicia Barnard AMOZURRUTIA } \\
\text { Arien Gonzalez CRESPO }\end{array}$ & - & - & 9 & - & $\begin{array}{l}7 \\
1\end{array}$ & \\
\hline $\begin{array}{l}\text { Armando B. Ma the ro da SILVA* } \\
\text { Georgete MedLeg RODRIGUES }\end{array}$ & $\begin{array}{l}13 \\
20\end{array}$ & $\begin{array}{r}33 \\
2\end{array}$ & $\begin{array}{l}8 \\
2\end{array}$ & $\begin{array}{l}6 \\
8\end{array}$ & $\begin{array}{l}7 \\
6\end{array}$ & - \\
\hline $\begin{array}{l}\text { Ingrid BECK } \\
\text { Ivone Pereira de SA \& Pavlo Xavier } \\
\text { dos SANTOS } \\
\text { Joa O VIEIRA. }\end{array}$ & $\begin{array}{l}10 \\
18\end{array}$ & - & ; & 1 & $\begin{array}{l}9 \\
2 \\
2\end{array}$ & - \\
\hline José Maria JARDIM* & 21 & - & 14 & 4 & - & - \\
\hline $\begin{array}{l}\text { Julio Cesar CARDOSO \& André } \\
\text { Rirardo LUZ } \\
\text { Lucia Maria Veloso de OLIVEIRA }\end{array}$ & 15 & 5 & 1 & 13 & 15 & - \\
\hline Luciana DURANTI & & - & $\cdot$ & - & 7 & - \\
\hline $\begin{array}{l}\text { Mar ia Luiza de Almeida CA.MPOS } \\
\text { Mays M. Mena MUGiCA }\end{array}$ & 14 & 2 & ; & - & $\frac{1}{7}$ & i \\
\hline $\begin{array}{l}\text { Rosely Curi RONDNELLI \& } \\
\text { Claudia Lacombe ROCHA }\end{array}$ & 7 & 1 & - & - & 2 & - \\
\hline $\begin{array}{l}\text { Sergio Conde de A toite SILVA } \\
\text { Suzame Alves MARTINS }\end{array}$ & $\begin{array}{r}4 \\
30\end{array}$ & 2 & : & 2 & 3 & : \\
\hline Theo THOMASSEM & & - & - & - & - & - \\
\hline Wilson Santia go da SILVA & 19 & 3 & 1 & - & - & 1 \\
\hline Total & 188 & 48 & 45 & 34 & 76 & 3 \\
\hline
\end{tabular}

* Cada autor publicou dois trabalhos.

Fonte: Os autores.

Houve predominância do idioma nacional (português - Brasil). Pupim (2009) esclarece que, muitas vezes, "as obras eram traduzidas, o que implica dizer que o idioma preferido pelos autores era o português”.

Há que se ressaltar que o inglês ficou em segundo lugar, atrás apenas do português (Brasil), não sendo citado apenas por quatro autores, entre eles Theo Thomassem, que não mencionou nenhuma referência (há que se rever aqui se atende ao critério de cientificidade deste trabalho). Este resultado coincide com o de Pupim (2009).

Também merecem revisão sobre a cientificidade dos trabalhos, levando-se em conta o número de referências, Arien González Crespo e João Vieira.

\section{Ano de publicação das referências}

Foram identificadas 394 referências, assim distribuídas por períodos cronológicos: 1890-1919 (1); 1920-1929 (1), 1930-1939 (2), 1940-1949 (2), Ci. Inf., Brasília, DF, v. 39 n. 2, p.44-53, maio/ago., 2010 
1950-1959 (4), 1960-1969 (3), 1970-1979 (15), 1980-1989 (27), 1990-1999 (148), 2000-2006 (178) e sem data (13).

O período 2000-2006 foi o que teve maior número de referências bibliográficas: 178 . Isso pode indicar aumento considerável da disponibilidade de trabalhos da área a serem consultados e citados ou, ainda, uma baixa idade média da literatura citada no campo.

Destacam-se os seguintes autores, de acordo com os períodos estipulados (quadro 1):

\section{QUADRO 1}

Destaque a alguns autores referenciados por períodos cronológicos

\begin{tabular}{|c|c|}
\hline Período & Destaque a algums autores referenciados \\
\hline 1890 & IHGB \\
\hline $1920-1930$ & JENCKNSON, IHGB \\
\hline $1950-1959$ & DUCHEN \\
\hline $1970-1979$ & SCHELLENBERG (2), DELMAS e D OLIER, D,ALBERG, DELMAS, COOK \\
\hline $1980-1989$ & SCHELLEMBERG, DUCHEN, DURANTI \\
\hline $1990-1999$ & $\begin{array}{l}\text { COUTURE E LAJENEUSSE, BELLOTTO (3), JARDIM (11), PAES (3), DOLLAR, } \\
\text { ALBITE SILVA, LANCASTER (2), DURANTI, DURANTI E MACNEIL, DURANTI } \\
\text { E MACNEIL, LOPES (2), DUCHEN, FONSECA (4), FONSECA E JARDIM (2), } \\
\text { CAPURRO, LE COADIC (3), ROSSEAU E COUTURE (3), SILVA, SILVA RIBEIRO } \\
\text { RAMOS \& REAL (4), FIBEIRO, GOMES, COUTURE E DUCHARME (3), } \\
\text { MEADOWS, THOMASSEN }\end{array}$ \\
\hline $2000-2006$ & $\begin{array}{l}\text { SILVA A RIBEIRO (4), SILVA (6), COUTURE \& MARTNEAU (3), JARDIM (3), } \\
\text { JARDIM E FONSECA (2), COOK (5), DELMAS (2), RIBEIRO, THOMASSEN (4), } \\
\text { MRRANDA (2), COUTURE, BECK (2), DURANTI EASTWOOD \& } \\
\text { MACNEIL, GONZALEZ DE GOMEZ (2), RONDNELII (2), SCHELLEMBERG, } \\
\text { RIBEIRO (2), BECK, ROBREDO (2), DURANT, CASTELS, CAPURRO (2), } \\
\text { ALEITE SILVA, LARURGY, DOLLAR, FONSECA (4) }\end{array}$ \\
\hline
\end{tabular}

Fonte: Os autores.

Destacam-se as parcerias de autores que hoje são consolidados na literatura arquivística: Fonseca e Jardim, Rosseau e Couture, e Silva e Ribeiro. Além desses, apontam-se, em épocas diversas, referências de trabalhos publicados, republicados ou traduzidos, indicados pelas décadas: Duchein (1920 e 1990); Schellemberg (1970, 1980 e 2000); Cook (1970 e 2000); Duranti (1980, 1990 e 2000); Jardim (1990 e 2000); Fonseca (1990 e 2000); Silva (1990 e 2000); Thomassen (1990 e 2000).

\section{Autores das referências}

Para este quesito, foi necessário atribuir um valor de corte, tendo como critério o fato de o autor ter sido citado pelo menos três vezes. Tal decisão fez com que autores de expresão da ciência da informação e da arquivologia que não estivessem de acordo com o critério, tais como Rosely Curi Rondinelli, Luis Carlos Lopes, F. W. Lancaster, Antonio Miranda, Maria Nélida González de Gómez, Jaime Robredo e A. J. Meadows não aparecessem na lista dos mais citados. Pupim (2009) detectou que há muitos autores com menos de duas citações, o que para ela não significa que não sejam relevantes. "Ao contrário, muitos deles [...] são muito importantes". $\mathrm{Na}$ visão da autora, isso contribui para explicar que "a área [de arquivologia] se encontra em pleno desenvolvimento teórico".

Das 394 referências (236 foram citados uma vez e 40 foram citados pelo menos duas vezes), 118 autores foram citados pelo menos três vezes:

O número de citações por autor pode ser visualizado na tabela 9 .

TABELA 9

Autores mais citados nas referências

\begin{tabular}{|c|c|}
\hline Autor & $\begin{array}{r}\mathrm{N}^{\circ} \mathrm{de} \\
\text { referências }\end{array}$ \\
\hline José Maria JARDIM & 19 \\
\hline Armando B. Matheiro da SILVA & 15 \\
\hline Femanda FIBEIRO & 13 \\
\hline Carol CULTURE & 12 \\
\hline Maria Odila FONSECA & 12 \\
\hline Ge crgete Med leg RODRIGUES & 6 \\
\hline Luciana DURANTI & 6 \\
\hline Jütio RAMOS & 5 \\
\hline Manvel Luis REAL & 5 \\
\hline Terry cook & 5 \\
\hline Theo THOMLASSEN & 5 \\
\hline Jocelyre MARTINEAU & 4 \\
\hline Pedro de Abrev PEIXOTO & 4 \\
\hline The odore Roose velt SCHELENBERG & 4 \\
\hline He bisa Liberalli BELLOTTO & 3 \\
\hline Bruno DELMAS & 3 \\
\hline Darie1 DUCH.AFME & 3 \\
\hline Jean-Yves ROUSSEAU & 3 \\
\hline Charles M. DOLLAR & 3 \\
\hline F.BORJA DE AGUTNNALGADE & 3 \\
\hline Angética Alves CUNHA MARQUES & 3 \\
\hline Ingrid $B E C K$ & 3 \\
\hline Marilena Leite PAES & 3 \\
\hline Michel DUCHEIN & 3 \\
\hline Rafael CAPURRO & 3 \\
\hline Sérgio Conde de ALBITE SILVA & 3 \\
\hline Yves-Fran; ois Le COADIC & 3 \\
\hline
\end{tabular}

Fonte: Os autores. 
De acordo com os dados apresentados, identificaramse citações entre vários autores. Pupim (2009) assim compreende este fenômeno: "a área [de Arquivologia] não poderia ser considerada consolidada, já que as citações se encontram pulverizadas por inúmeros autores e havia poucos autores com três ou mais citações, o que denota a não concordância dos referenciais teóricos entre os produtores dos trabalhos fonte".

Dos autores mais citados identificados na pesquisa que foi realizada em 2009 por Medeiros, Nodare e Araújo, coincidiram com a pesquisa realizada por Pupim (2009): Theodore Roosevelt Schelenberg; José Maria Jardim; Michel Duchein; Marilena Leite Paes; Carol Culture; Jean-Yves Rousseau; Heloísa Liberalli Bellotto (tabela 10).

TABELA 10

Autores mais citados e identificados por Medeiros, Nodare e Araújo (2009) versus Autores mais citados e identificados por Pupim (2009)

\begin{tabular}{l|r|r}
\hline \multicolumn{1}{c|}{$\begin{array}{c}\text { Autores } \\
\text { mais citados }\end{array}$} & $\begin{array}{r}N^{\circ} \text { de } \\
\text { referências }\end{array}$ & $\begin{array}{r}N^{\circ} \text { de } \\
\text { referências } \\
\text { Pupim (2009) }\end{array}$ \\
\hline Jose Maria JARDIM & 19 & 8 \\
Carol CULTURE & 12 & 4 \\
Theodore Roosevelt SCHELENBERG & 4 & 12 \\
Heloisa Liberalli BELLOTTO & 3 & 3 \\
Jean-Yves ROUSSEAU & 3 & 4 \\
Marilena Leite PAES & 3 & 7 \\
Michel DUCHEIN & 3 & 7 \\
\hline
\end{tabular}

Fonte: Os autores.

Há que se levar em conta textos e obras consagradas publicados por Schelenberg, Duchein, Culture, Rousseau e o Dicionário de Arquivística, de Bellotto, que interferem positivamente na citação desses autores. Também há que se pesquisar se os autores mais citados nesta pesquisa não apareceram na listagem de Pupim (tabela 11) por terem obras consagradas publicadas a partir de 2000, por exemplo:
TABELA 11

Autores mais citados e identificados por Medeiros, Nodare e Araújo (2009) e não identificados por Pupim (2009)

\begin{tabular}{l|r}
\hline $\begin{array}{c}\text { Autores mais citados } \\
\text { e não ide nufific ados por Pupim (2009) }\end{array}$ & $\begin{array}{r}\text { No de } \\
\text { citaçóes }\end{array}$ \\
\hline Armando B. Mathe iro da SILVA & 15 \\
Fernanda RIBEIRO & 13 \\
Maria Odila FONSECA & 12 \\
Lviana DURANTI & 6 \\
Terry COOK & 5 \\
Theo THOMASSEN & 5 \\
Rafael CAPURRO & 3 \\
Yves-François Le COADIC & 3 \\
\hline
\end{tabular}

Fonte: Os autores.

\section{CONSIDERAÇÕES FINAIS}

Sabe-se que o número reduzido de dados coletados pode dar margem a dúvidas quanto ao caráter conclusivo desta pesquisa, ainda mais se se parte do princípio de que a ciência da informação se relacionada com várias áreas do conhecimento.

Mesmo assim, arrisca-se aqui a afirmar que a análise dos dados coletados apontou que existe estreita relação do conhecimento produzido na área de arquivologia com o conhecimento gerado pela área da ciência da informação. Tal afirmação apoia-se, primeiro, na categorização das correntes teóricas da ciência da informação que puderam ser identificadas nos trabalhos selecionados; e, segundo, na identificação dos autores citados na ciência da informação e que também foram identificados nos fascículos do periódico analisado.

Um fato que pode ter impedido o aparecimento mais expressivo de citação de autores da área da ciência da informação é a especialidade do periódico, voltado para a área da arquivologia. Mesmo assim, o que se vê é que autores da arquivologia citam autores consagrados da ciência da informação, contradizendo a noção de que a arquivologia era uma disciplina auxiliar da administração e da história. 
As relações do conhecimento produzido na área de arquivologia com a ciência da informação

Quanto às correntes teóricas da ciência da informação, a identificação dos trabalhos selecionados vai além do caráter sistêmico e tecnicista, chegando a tratar de questões relativas à gestão da informação e do conhecimento e trazendo o usuário para o centro dos estudos. Tudo isso indica um caminho que levará ao amadurecimento da área como ciência social aplicada, em um paradigma social, tal como acontece com a ciência da informação. Mais ainda, tudo isso ajuda a reafirmar seu estreito relacionamento com e como ciência da informação.

No que se refere às limitações do estudo, além do número reduzido de dados coletados, aponta-se a necessidade de realizar as pesquisas apontadas ao longo do texto, bem como ampliar a coleta a todos os fascículos do referido periódico, buscar número maior de referencial teórico e desenvolver outras análises estatísticas para cruzamento dos dados.

Artigo submetido em 06/08/2010 e aceito em 22/02/2011.

\section{REFERENNCIAS}

ARAUJO, C. A. A. Correntes teóricas da Ciência da Informação. Ciência da Informação, v. 38, n.3, p. 192-204, set./dez. 2009.

CAPURRO, Rafael. Epistemologia e ciência da informação. In: ENCONTRO NACIONAL DE PESQUISA EM CIÊNCIA DAINFORMAÇÃO, 5., 2003, Belo Horizonte. Anais eletrônicos... Belo Horizonte: Associação Nacional de Pesquisa e Pós-Graduação em Ciência da Informação e Biblioteconomia, 2003. 1 CD-ROM.

FONSECA, Maria Odila Kahl. Arquivologia e ciência da informação. Rio de Janeiro: Ed. FGV, 2005.

GONZÁLEZ DE GOMÉZ, Maria Nélida. Metodologia da pesquisa no campo da Ciência da Informação. DataGramaZero - Revista de Ciência da Informação, v. 1, n. 6, dez. 2000. Disponível em: <http:// www.datagramazero.org.br/dez00/Art_03.htm>.

JARDIM, José Maria. A produção de conhecimento arquivístico: perspectivas internacionais e o caso brasileiro (1990-1995). Ciência da Informação, Brasília, v. 27, n. 3, 1998. Disponível em: <http://www. scielo.br/pdf/ci/v27n3/27n3a01.pdf >.

PUPIM, Eliana Kátia. Análise bibliométrica em Arquivologia: enfoque no periódico Arquivo \& Administração. In: SEMINÁRIO EM CIÊNCIA DA INFORMAÇÃO, 3., 2009. [mensagem pessoal]. Mensagem recebida por: < biblioteca@globo.com> em $1^{\circ}$ dez. 2009.

SILVA, Armando Malheiro da. A Informação: da compreensão do fenômeno e construção do objecto científico. Porto: Edições Afrontamento; CETAC, 2006. 